\title{
Pengaruh Jumlah Sekat Aliran Lapisan Pengisi Terhadap Unjuk Kerja Menara Pendingin (Cooling Tower)
}

\author{
${ }^{1}$ Sumarjianto, ${ }^{2}$ Gatut Rubiono, ${ }^{3}$ Ikhwanul Qiram \\ 1) Alumni Prodi Teknik Mesin Universitas PGRI Banyuwangi \\ ${ }^{2)}$ Prodi Teknik Mesin Universitas PGRI Banyuwangi, Jl. Ikan Tongkol 22 \\ Banyuwangi \\ Email: rubionov@yahoo.com
}

\begin{abstract}
The cooling tower has a working principle for cool the water fluid forcibly using a fan or blower. This Research aims to determine the effect of the number of filler bulkheads and the angle of openingvalve to the cooling tower work efficiency. This research uses type induced draft cooling tower with flow opposite the tool size laboratory scale. Research variables include 3 variations in the number of bulkheads (2 bulkheads, 3 bulkhead and 4 bulkheads) and 3 variations of valve opening angles (30, 45 and 60). Result measurements in the form of water discharge data, water temperature data, air temperature data, temperature data environment (Twb) and temperature difference data. Water discharge data is measured with a flow meter and stop watch. Temperature data measured with a Digital Thermometer. Data were collected 5 times repetition of each data. The measurement results are taken the average value for measures the discharge, temperature, heat transfer rate and efficiency of the cooling tower. The results showed that the number of bulkheads and the angle of the opening valve has an effect on the working efficiency of Cooling Tower which is getting more the greater the number of bulkheads the greater the cooling tower work efficiency and vice versa but the greater the valve opening angle the smaller the cooling tower efficiency.

The maximum efficiency obtained from this study is at the number of bulkheads 4 and the valve opening angle of 30 with a Cooling Tower efficiency value of $78.40 \%$.
\end{abstract}

\section{Keywords: Cooling Tower, Cooling Tower Efficiency, Heat Transfer Rate, Approach and Cooling Range}

\section{PENDAULUAN}

Pada saat ini banyak sekali bermunculan industri besar. Industri-industri tersebut memerlukan mesinmesin besar sebagai alat penunjang dalam semua proses produksinya. Mesin-mesin ini mengeluarkan kalor sebagai efek samping dari proses produksinya, sehingga dibutuhkan pendingin untuk kelangsungan kerjanya. Pendingin yang sering digunakan dan murah adalah air. Air yang digunakan dalam proses pendinginan akan keluar dalam kondisi panas, dan apabila air langsung dibuang atau dikembalikan ke tempat asal air maka akan menimbulkan polusi thermal. Polusi thermal adalah meningkatnya suhu lingkungan sebagai akibat dari proses produksinya ( dalam hal ini air ). Solusi untuk mengatasi hal ini adalah dengan menggunakan sistem pendingin. Ada berbagai macam sistem pendingin yang digunakan untuk mendinginkan air pendingin mesin, salah satunya adalah menggunakan menara pendingin (Cooling Tower). Sistem ini sangat efektif untuk mendinginkan air pendingin mesin dengan kapasitas yang banyak. Berbeda dengan mesin-mesin kecil yang hanya memerlukan Radiator sebagai sistem pendingin untuk mendinginkan air pendingin mesin. Menara pendingin dilihat dari cara pengaliran udaranya ada 2 jenis yaitu Natural Draft dan Mecanical Draft. Natural Draft adalah aliran udara dalam menara pendingin karena perbedaan suhu dari udara sehingga akan mengalir secara alami (Natural). Sedangkan Mecanical Draft adalah sistem pengaliran udara dengan paksaan atau menggunakan kipas pengalir udara. Mecanical Draft ada beberapa macam salah satunya adalah Induced Draft (aliran yang belawanan). Induced Draft adalah arah aliran udara berlawanan dengan arah aliran air yang didinginkan, yaitu air mengalir dari puncak menara dan udara dialirkan dari bawah menara.

Penelitian tentang Cooling Tower telah banyak dilakukan, hal ini menunjukkan bahwa penelitian tentang Cooling Tower sangat penting untuk dilakukan. Mulyono (Teknik Mesin Politeknik Negeri Semarang, 
2010) meneliti tentang Menara Pendingin basah Induced-Draft aliran lawan arah dengan judul Analisa Beban Kalor Menara Pendingin Basah Induced-Draft Aliran Lawan Arah. Naif Fuhaid (Widya Teknika, 2008) meneliti tentang besar sudut kemiringan bahan pengisi dengan judul Pengaruh Sudut Kemiringan Sekat terhadap Unjuk Kerja Menara Pendingin Air. Untuk mendapatkan hasil pertukaran panas yang efisien diperlukan komponen tambahan yang berupa bahan pengisi atau sekat ( fill).

Bahan pengisi berguna untuk memfasilitasi perpindahan kalor guna memaksimalkan kontak udara dengan air. Dewasa ini terus dikembangkan besar sudut dari susunan bahan pengisi, jenis bahan pengisi dan bentuk susunan bahan pengisi yang dapat memberikan tingkat keefektifan pendinginan yang memadai. Fakta ini mendorong peneliti merealisasikan sebuah penelitian untuk mendapatkan suatu jumlah susunan bahan pengisi atau fill sehingga akan didapatkan sebuah Menara Pendingin yang lebih efektif.

\section{METODOLOGI PENELITIAN}

1. Variabel bebas pada penelitian ini yaitu :

a. Pengujian dengan tiga macam jumlah sekat pengisi
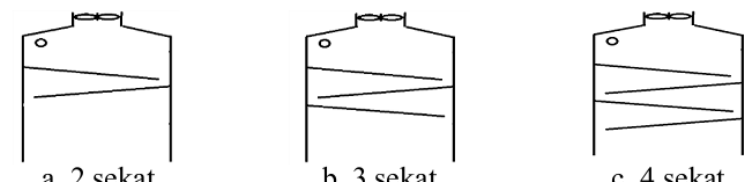

a. 2 sekat

b. 3 sekat

c. 4 sekat

b. 3 macam pembukaan katup aliran air pendingin yaitu sudut $30^{\circ}$, sudut $45^{\circ}$, dan sudut $60^{\circ}$.

c. Pengujian dilakukan pada sudut kemiringan sekat 5 .

2. Variabel terikat pada penelitian ini adalah:

a. Pengukuran debit air.

b. Pengukuran temperatur air.

c. Pengukuran Temperatur udara.

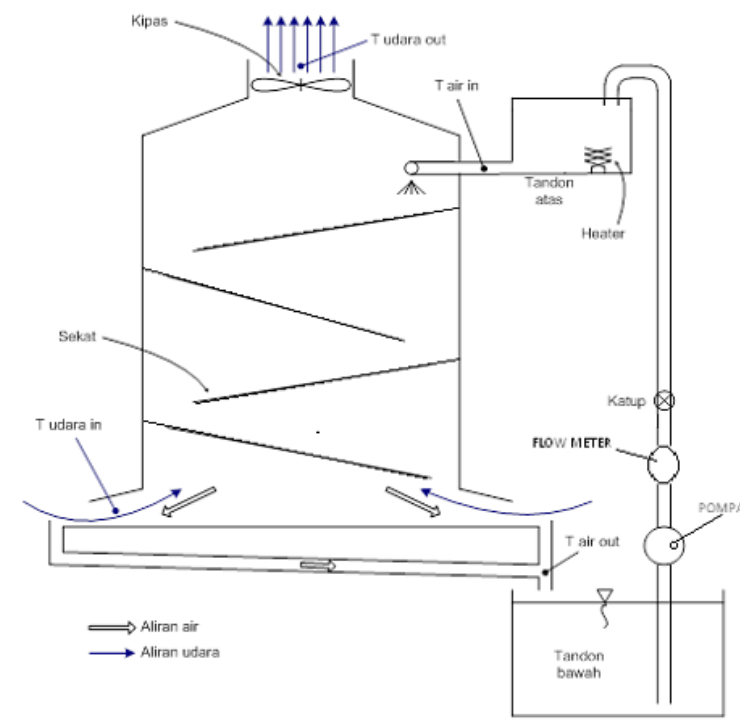

Gambar 1. Skema alat Menara Pendingin
Alat

Alat yang digunakan antara lain

1. Pompa air, dengan spesifikasi tegangan 220240volt/50 Hz, Daya 23 watt, Head maksimal 1,2 m, Q maksimal $1200 \mathrm{~L} / \mathrm{h}$ ) untuk mensirkulasikan air.

2. Flow meter, dengan spesifikasi: diameter $1 / 2$ ", Q maksimal 1,5/h, ketelitian 0,0001 untuk mengukur volume air.

3. Stop Watch dari Aplikasi Hand Phone merk Cross type G900T untuk mengukur waktu alir air.

4. Kran air jenis Ball $1 / 2$ ", merek Blitz untuk mengatur jumlah debit yang divariasi.

5. Water Heater, ( merek Automatic, tegangan 220 240 volt/ $50 \mathrm{~Hz}$, Daya 23 watt ) untuk memanaskan air.

6. Kipas angin listrik, (merek Winner, tegangan 220 - 240 volt/50-60 Hz, 14/12 W, 0,08/0,07 A ) untuk mengalirkan udara dalam sistem.

7. Thermometer digital untuk mengukur temperatur air, temperatur udara dan temperatur lingkungan.

a.

b. Bahan

Adapun bahan yang digunakan antara lain

1. Air.

2. Cat.

3. Lem kaca ( sealant )

4. Pipa air.

5. Acrilic tebal $2 \mathrm{~mm}$.

6. Plat besi tebal $0,8 \mathrm{~mm}$.

7. Baut, mur dan bahan lainnya.

III. ANALISA DATA DAN PEMBAHASAN

TABEL 1

DATA HASIL PENGUKURAN DEBIT AIR

\begin{tabular}{|c|c|c|c|c|c|c|c|}
\hline \multirow{3}{*}{$\begin{array}{c}\text { Jumlah } \\
\text { Sekat }\end{array}$} & $\begin{array}{c}\text { Bukaan } \\
\text { katup } \\
\text { (degrees) }\end{array}$ & \multicolumn{1}{|c|}{$\begin{array}{l}\text { Volume } \\
\text { (liter) }\end{array}$} & \multicolumn{5}{|c|}{ Waktu (detik) } \\
\hline \multirow{3}{*}{2} & 30 & 10 & 400,70 & 400,20 & 401,80 & 401,90 & 400,20 \\
\hline & 45 & 10 & 193,50 & 194,30 & 194,60 & 193,80 & 195,10 \\
\hline \multirow{3}{*}{3} & 60 & 10 & 158,90 & 161,40 & 161,90 & 162,00 & 161,80 \\
\hline \multirow{3}{*}{3} & 30 & 10 & 400,70 & 400,20 & 401,80 & 401,90 & 400,20 \\
\cline { 2 - 8 } & 45 & 10 & 193,50 & 194,30 & 194,60 & 193,80 & 195,10 \\
\cline { 2 - 8 } & 60 & 10 & 158,90 & 161,40 & 161,90 & 162,00 & 161,80 \\
\hline \multirow{3}{*}{4} & 30 & 10 & 400,70 & 400,20 & 401,80 & 401,90 & 400,20 \\
\cline { 2 - 8 } & 45 & 10 & 193,50 & 194,30 & 194,60 & 193,80 & 195,10 \\
\cline { 2 - 8 } & 60 & 10 & 158,90 & 161,40 & 161,90 & 162,00 & 161,80 \\
\hline
\end{tabular}

TABEL 2

DATA HASIL PENGUKURAN TEMPERATUR AIR

\begin{tabular}{|c|c|c|c|c|c|c|c|c|c|c|c|}
\hline \multirow{2}{*}{$\begin{array}{c}\text { Jumlah } \\
\text { Sekat }\end{array}$} & \multirow{2}{*}{$\begin{array}{c}\text { Bukaan } \\
\text { Katup } \\
\text { (degrees) }\end{array}$} & \multicolumn{5}{|c|}{ Suhu Air Masuk $\left({ }^{\circ} \mathrm{C}\right)$} & \multicolumn{5}{|c|}{ Suhu Air Keluar $\left({ }^{\circ} \mathrm{C}\right)$} \\
\hline & & 1 & 2 & 3 & 4 & 5 & 1 & 2 & 3 & 4 & 5 \\
\hline \multirow{3}{*}{2} & 30 & 61,50 & 61,40 & 61,50 & 61,20 & 61,30 & 39,20 & 39,40 & 39,30 & 39,50 & 39,30 \\
\hline & 45 & 61,30 & 61,30 & 61,20 & 61,30 & 61,50 & 41,00 & 41,10 & 41,00 & 41,10 & 41,20 \\
\hline & 60 & 61,50 & 61,40 & 61,20 & 61,40 & 61,10 & 44,00 & 44,10 & 43,80 & 43,90 & 44,10 \\
\hline \multirow{3}{*}{3} & 30 & 60,30 & 60,50 & 60,30 & 60,10 & 60,30 & 38,10 & 38,00 & 38,50 & 38,10 & 37,90 \\
\hline & 45 & 60,60 & 60,60 & 60,60 & 60,70 & 60,50 & 40,20 & 40,30 & 40,30 & 40,20 & 40,40 \\
\hline & 60 & 61,40 & 61,40 & 61,20 & 61,40 & 61,10 & 42,70 & 42,60 & 42,40 & 42,50 & 42,50 \\
\hline & 30 & 60,50 & 60,40 & 60,50 & 60,40 & 60,60 & 37,80 & 37,90 & 37,80 & 37,60 & 37,70 \\
\hline & 45 & 62,30 & 62,30 & 62,50 & 62,30 & 62,20 & 40,10 & 40,00 & 40,10 & 40,30 & 40,10 \\
\hline & 50 & 61,20 & 61,30 & 61,30 & 61,50 & 61,30 & 42,10 & 42,10 & 42,40 & 42,10 & 41,8 \\
\hline
\end{tabular}




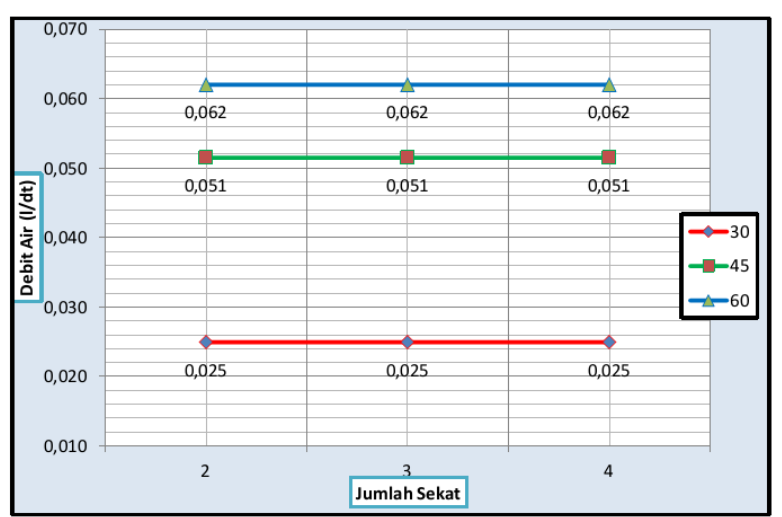

Gambar 2. Grafik variasi debit air

Grafik variasi debit air seperti pada gambar 2 menunjukkan bahwa besar debit air cenderung selalu sama pada variasi jumlah sekat pengisi, namun akan cenderung berubah pada variasi sudut bukaan katup. Debit air akan naik apabila sudut bukaan katup bertambah besar dan akan turun pada saat sudut bukaan katup diperkecil. Debit air maksimum terjadi pada bukaan katup 60 yaitu sebesar 0,062 1/dt, sedangkan debit air terkecil berada pada bukaan katup 30 yaitu sebesar $0,025 \mathrm{l} / \mathrm{dt}$.

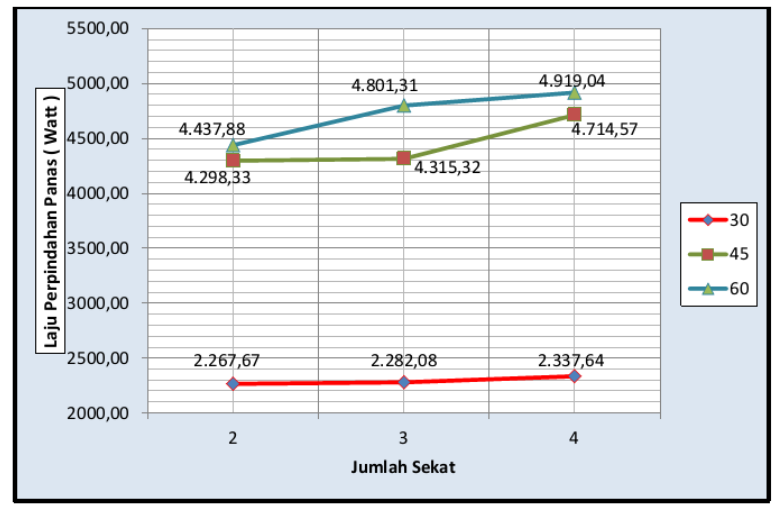

Gambar 3. Gafik perhitungan laju perpindahan panas

Grafik hasil perhitungan laju perpindahan panas seperti pada gambar 3 menggambarkan bahwa laju perpindahan panas cenderung naik pada setiap variasi jumlah sekat yang semakin banyak dan variasi besar sudut bukaan katup yang semakin besar Laju perpindahan panas tertinggi berada pada vaariasi jumlah sekat 4 dan variasi bukaan katup 60 yaitu sebesar 4.919,04 watt, sedangkan laju perpindahan panas yang terendah berada pada variasi jumlah sekat 2 dan variasi bukaan katup 30 yaitu sebesar 2.267,67

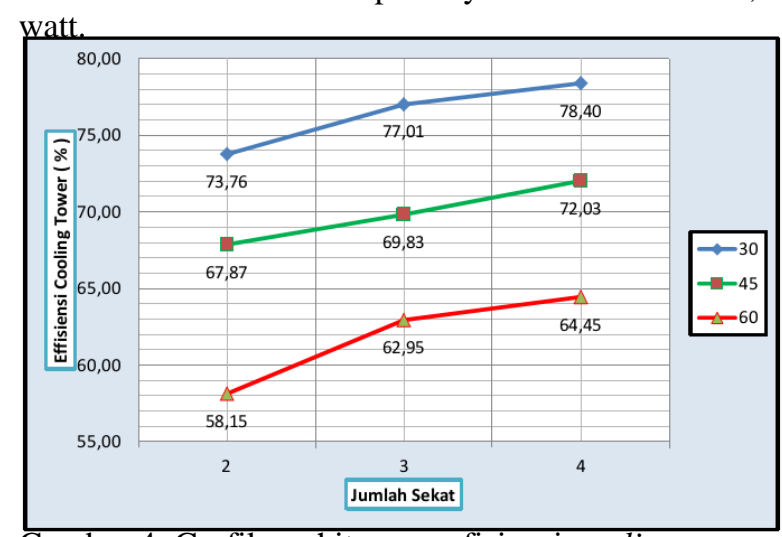

Gambar 4. Grafik perhitungan efisiensi cooling tower

\section{KESIMPULAN DAN SARAN}

\section{Kesimpulan}

1. Besar sudut bukaan katup berpengaruh terhadap besarnya debit air, dimana semakin besar sudut bukaan katup semakin besar debit air dan semakin kecil bukaan katup juga semakin kecil debit airnya

2. Besar sudut bukaan katup juga berpengaruh terhadap laju perpindahan panas dan efisiensi cooling tower yaitu semakin besar sudut bukaan katup semakin besar laju perpindahan panasnya akan tetapi apabila semakin besar sudut bukaan katupnya maka semakin kecil efisiensi cooling towernya dan demikian pula sebaliknya.

3. Jumlah sekat pengisi tidak berpengaruh terhadap debit air.

4. Jumlah sekat pengisi mempengaruhi laju perpindahan panas dan efisiensi cooling tower, dimana semakin banyak jumlah sekat pengisi laju perpindahan panas semakin besar dan semakin banyak sekat efisiensi cooling tower juga semakin tinggi.

5. Laju perpindahan panas terbesar berada pada posisi jumlah sekat 4 dan sudut bukaan katup $60^{\circ}$ dengan nilai sebesar 4.919,04 watt, sedangkan laju perpindahan panas terkecil berada pada posisi jumlah sekat pengisi 2 dan bukaan katup $30^{\circ}$ dengan nilai sebesar 2.267,67 watt.

6. Efisiensi cooling tower maksimum dengan nilai efisiensi 78,40\% berada pada posisi jumlah sekat 4 dan sudut bukaan katup $30^{\circ}$, sedangkan nilai efisiensi minimum dengan nilai efisiensi 58,15\% berada pada jumlah sekat 2 dan sudut bukaan katup $60^{\circ}$

7. Saran

1. Untuk peneliti selanjutnya dapat mengadakan penelitian dengan variasi bentuk sekat pengisi yang berbeda misalnya bentuk V, dan bentuk dobel zig zag.

2. Bahan sekat pengisi sebaiknya digunakan bahan yang tahan terhadap panas serta mudah menghantarkan panas agar nilai efisiensi lebih baik.

3. Sebaiknya heater yang digunakan adalah heater yang berkapasitas besar agar panas yang dihasilkan dapat lebih cepat.

4. Bahan yang didinginkan dapat pula divariasi misalkan digunakan bahan air, campuran air dengan Water Radiator Coolant dan Water Radiator Coolant murni.

\section{DAFTAR PUSTAKA}

[1] A. Walujodjati , 2005, Pengaruh Kecepatan Udara terhadap Temperatur bola Basah, Bola Kering pada Menara Pendingin.

[2] El-Wakil, M.M., diterjemahkan Jasjfi, E, 1992, Instalasi Pembangkit Daya (Judul asli : Power Plant Technology) Penerbit Erlangga, Jakarta.

[3] Fuhaid, Naif, 2008, Pengaruh Sudut Kemiringan Sekat terhadap Unjuk Kerja Menara Pendingin Air

[4] Haar, L, Gallagher, J.S., dan Kell, G.S., 1984, NBS/NRC SteamTables, The United States Secretary of Commerce, USA 
[5] J.P. Holman, Perpindahan Kalor, Edisi keenam. Erlangga: 1997

[6] Kreith,Frank dan Arko prijono. Prinsip-Prinsip Perpindahan Panas.Edisi ketiga. Erlangga: Jakarta.1997

[7] Mulyono, 2010, Analisa Beban Kalor Menara Pendingin Basah Induced-Draft Aliran Lawan Arah

[8] Ramarao; Shivaraman ,2004; Ministry of Power India. Cooling Tower In Energy Efficiency in Electricity Utilitas . Chapter 7 , 135-151, India Bureau of Energy Efficiency.

[9] Stoecker, F.W; Jerold, W.J , alih bahasa Supratman Hara, 1987, Refrigerasi dan Pengkondisian Udara, Edisi ke 2, Penerbit Erlangga, Jakarta. 